\title{
Siloxy Esters as Traceless Activator of Carboxylic Acids: Boron-Cat- alyzed Chemoselective Asymmetric Aldol Reaction
}

\author{
Taiki Fujita, ${ }^{\dagger}$ Mina Yamane, ${ }^{\dagger}$ W. M. C. Sameera, $§$ Harunobu Mitsunuma, ${ }^{*}{ }^{\dagger}$ Motomu Kanai*, ${ }^{\dagger}$ \\ ${ }^{\dagger}$ Graduate School of Pharmaceutical Sciences, The University of Tokyo, Hongo, Bunkyo-ku, Tokyo 113-0033, Japan \\ §Institute of Low Temperature, Hokkaido University, Kita-19, Nishi-8, Kita-Ku, Sapporo 060-0819, Japan
}

\begin{abstract}
The catalytic asymmetric aldol reaction of carboxylic acids is among the most useful reactions for the synthesis of biologically active compounds and pharmaceuticals. Despite the existence of many prominent reports, no general method is available to incorporate the aldol motif into complex carboxylic acids and their derivatives at late stages. Chemoselective catalytic asymmetric aldol reaction of multifunctional carboxylic acids is difficult to achieve, due to the high basicity required for enolization and the poisonous chelation of $\beta$-hydroxy acid products to Lewis acid catalysts. Herein, we identified that preconversion of carboxylic acids to siloxy esters facilitated the boron-catalyzed direct aldol reaction, leading to the development of carboxylic acid-selective, catalytic asymmetric aldol reaction applicable to multifunctional substrates. The asymmetric boron catalyst stereodivergently controlled the products' stereochemistry depending on the catalyst's chirality, not on the stereochemical bias of substrates. Computational studies rationalized the mechanism of the catalytic cycle and the stereoselectivity, and proposed $\mathrm{Si} / \mathrm{B}$ enediolates as the active species for the asymmetric aldol reaction. The silyl ester formation facilitated both enolization and catalyst turnover through acidifying the $\alpha$-proton of substrates and attenuating poisonous Lewis bases to the boron catalyst.
\end{abstract}

\section{INTRODUCTION}

The carboxyl group is a common functional group existing in a wide range of organic molecules, especially in biologically active natural products and pharmaceuticals: e.g. nonsteroidal anti-inflammatory drugs (NSAIDs) ${ }^{1}$ and antibiotics. ${ }^{2}$ Therefore, catalytic, chemoselective, and asymmetric $\mathrm{C}-\mathrm{C}$ bond-formation of carboxylic acids containing multiple functional groups is useful in complex molecule synthesis and late-stage structural diversifications of drug leads for optimizing their pharmaceutical properties. ${ }^{3}$

Due to the high acidity of carboxylic acids compared to other common functional groups, chemoselective recognition and activation of carboxylic acids is possible through reversible catalyst-substrate covalent bond- or salt-formation. Yamamoto reported a pioneering example of boronic acid-catalyzed electrophilic activation of carboxylic acids in the presence of amines for amidation (Scheme 1a). ${ }^{4,5}$ Electron-withdrawing arylboronic acids chemoselectively formed acyloxyboron intermediates with substrate carboxylic acids to enhance their electrophilicity. Yu reported site-selective, palladium-catalyzed $\mathrm{C}-\mathrm{H}$ bond functionalizations of carboxylic acids at distal positions ( $\beta$ - or farther positions) to the carboxyl group and their applications to natural product synthesis (Scheme 1b). ${ }^{6}$ The carboxylate group worked as a directing group of the palladium catalyst by coordination, realizing highly practical site-selective $\mathrm{C}$ $\mathrm{H}$ functionalizations. Our group reported chiral boronate-catalyzed nucleophilic activation of carboxylic acids through enolization, enabling chemoselective and asymmetric Mannich reaction and $\alpha$-allylation of carboxylic acids (Scheme 1c). ${ }^{7,8}$ Chiral diboron enediolate $\mathbf{1}^{9}$ was proposed as the active species for those reactions. Due to the high oxophilicity of the boron catalyst, however, this enolization method was not effective in

Scheme 1. Catalytic Chemoselective Activation of Carboxylic Acids

a. Electrophilic activation ${ }^{\text {ref } 4,5}$

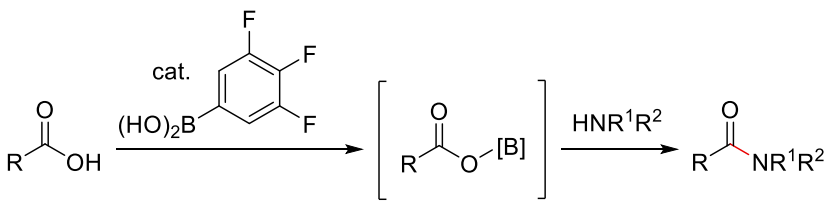

b. Regioselective $\mathrm{C}-\mathrm{H}$ activation ${ }^{\text {ref } 6}$

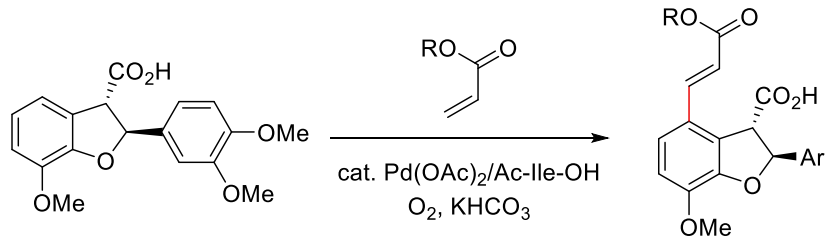

c. Nucleophilic activation

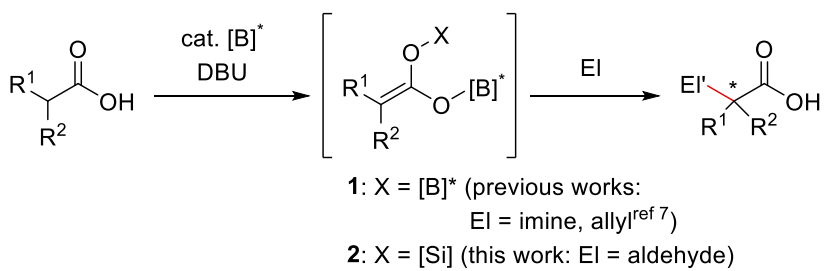


promoting a catalytic asymmetric aldol reaction of carboxylic acids, ${ }^{10}$ another fundamental and synthetically useful $\mathrm{C}-\mathrm{C}$ bond-forming reaction. ${ }^{11-14}$ Here we found that in-situ pre-conversion of carboxylic acids to siloxy esters dramatically facilitated the boron-catalyzed, carboxylic acid-selective asymmetric aldol reaction. The siloxy group worked as a traceless activator, allowing for the direct use of carboxyl group-containing multifunctional drugs and natural products themselves as substrates of catalytic asymmetric aldol reactions. ${ }^{15} \mathrm{We}$ propose $\mathrm{Si} / \mathrm{B}$ enediolates $\mathbf{2}$ as the active species for this reaction. Since the boron catalyst did not promote aldol reactions of simple esters (e.g. $t \mathrm{Bu}$ ester), the reactivity is unique to siloxy esters.

\section{RESULTS AND DISCUSSION}

We began optimization of the reaction between benzaldehyde (3a) and propionic acid (4a) using a chiral boron catalyst generated from either $\mathrm{BH}_{3} \bullet \mathrm{SMe}_{2}$ or $(\mathrm{AcO})_{4} \mathrm{~B}_{2} \mathrm{O}$ with ligand $\mathbf{L 1}^{7,10}$ (Table 1). In the absence of any additives, the yield of product 5aa was up to the loading amount of the boron catalyst (entries 1 and 2). We attributed the lack of catalyst turnover to the high stability of the catalytically inactive boron aldolate intermediate 6. To facilitate catalyst turnover, we added silylating reagents. ${ }^{13 a}$ Although using $\mathrm{BH}_{3} \bullet \mathrm{SMe}_{2}$ as a boron source did not produce $5 \mathbf{a a}$ in the presence of $\mathrm{Me}_{3} \mathrm{SiCl}$ (entry 3), $(\mathrm{AcO})_{4} \mathrm{~B}_{2} \mathrm{O}$ afforded the product in $42 \%$ yield (entry 4 ). Treatment of $\mathbf{4 a}$ with $\mathrm{Me}_{3} \mathrm{SiCl}$ prior to the aldol reaction further improved the yield to $48 \%$ (entry 5). NMR studies revealed that $\mathbf{4 a}$ was converted to its silyl ester by this treatment. ${ }^{16}$ Screening silylating reagents led us to identify $(\mathrm{EtO})_{3} \mathrm{SiCl}$ as the optimum additive regarding product yield, affording 5aa in 92\% yield with 13/1 dr, but with only $3 \%$ ee (entry 6 ). The selectivity slightly improved to $15 / 1 \mathrm{dr}$ and $6 \%$ ee in THF, despite yield lowered to $71 \%$ (entry 7 ). No reaction proceeded in the absence of the boron catalyst (entry 8).

To improve enantioselectivity, we next studied valine-derived ligands with various $\mathrm{N}$-aryl sulfonyl groups. Enantioselectivity increased according to the number of fluorine substituents on the aryl group of ligands $\mathbf{L 1}-\mathbf{L} 4,^{7 \mathrm{~b}, 10 \mathrm{a}, 17}$ but diastereoselectivity decreased accordingly (entries 7 and 9-11). To optimize the electronic properties of the sulfonyl group, we substituted the 4-fluorine atom of $\mathbf{L 4}$ with an electron-donating MeO (L5: entry 12) or $\mathrm{Me}_{2} \mathrm{~N}$ (L6: entry 13) group: using L6 afforded balanced $\mathrm{dr}$ and ee (entry 13). Finally, reducing the amount of DBU to 3.5 equiv and concentration to $0.1 \mathrm{M}$ afforded $5 \mathbf{a a}$ in $69 \%$ yield with $16 / 1 \mathrm{dr}$ and $86 \%$ ee (entry 14 ).

We then examined the substrate scope under the optimized conditions (Table 2). The scope of carboxylic acids was first investigated using benzaldehyde (3a). 3-Phenylpropionic acid (4b) furnished 5ab in high yield and stereoselectivities (89\%, >20/1 dr, $90 \%$ ee). The amount of boron catalyst could be reduced to $8 \mathrm{~mol} \%$ without significant erosion in reactivity and selectivity (76\%, 19/1 dr, 89\% ee). The reaction was applicable on a gram scale $(64 \%,>20 / 1 \mathrm{dr}, 90 \%$ ee). Carboxylic acids containing potentially reactive functional groups such as unsaturated $\mathrm{C}-\mathrm{C}$ bonds, halogens, and a hydroxy group were investigated $(\mathbf{4 c}-$ 4k). In all cases, the reaction proceeded smoothly with high diastereo- and enantioselectivity (5ac-5ak). The reaction was chemoselective at the $\alpha$-position of the carboxyl group in the presence of amide, ester, ketone, and nitrile functional groups, which are intrinsically more prone to enolization than the carboxyl group (5ag-5aj).
Next, the scope of aldehydes 3 was examined using carboxylic acid $\mathbf{4 b}$. A series of aromatic aldehydes bearing an electron-donating, an electron-withdrawing, and a naphthyl group were competent substrates (5bb-5fb). Introduction of a substituent at the ortho or meta position of the aromatic ring did not affect the result (5gb and $\mathbf{5 h b} v s$. $\mathbf{5 c b}$ ). Reactions with aliphatic aldehydes also proceeded in high yield and selectivity by increasing DBU to 5 equiv and the concentration to $0.3 \mathrm{M}(\mathbf{5 i b}-\mathbf{5 n b})$. Aliphatic aldehydes are especially difficult substrates for catalytic asymmetric direct aldol reactions because they can enolize easily under basic conditions. ${ }^{13}$

Table 1. Optimization of Reaction Conditions ${ }^{a}$

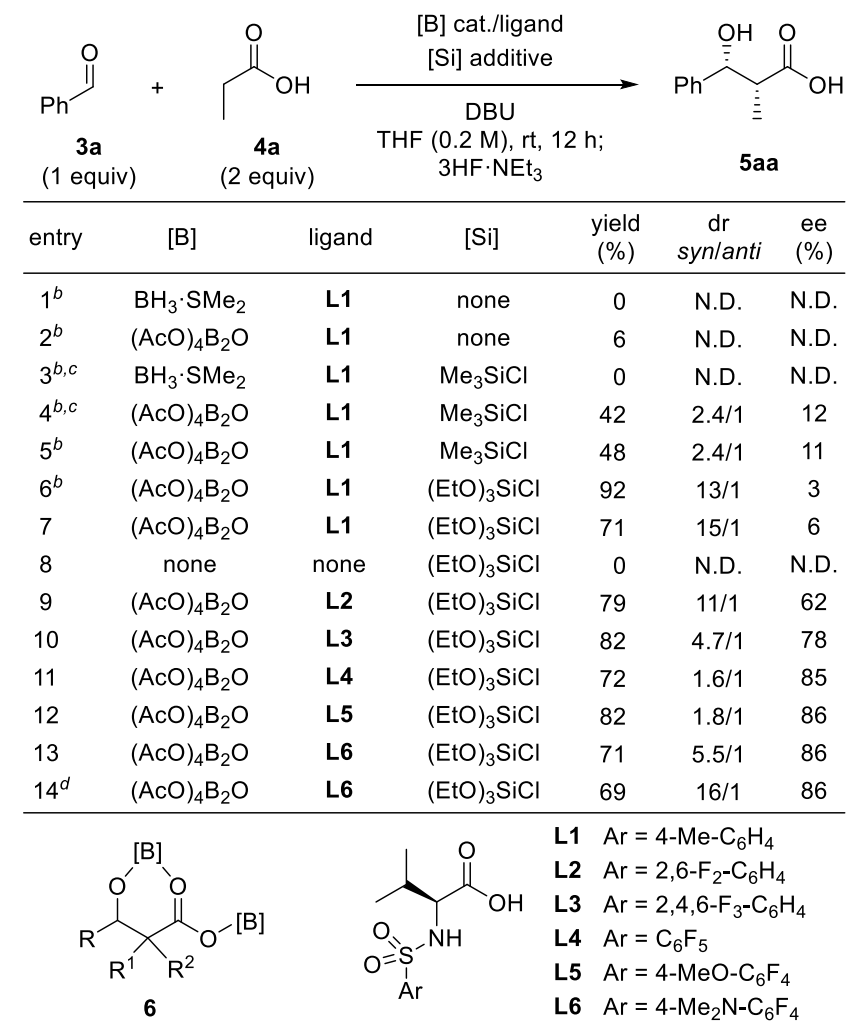

aStandard conditions (for entries 7-14): A mixture of 4a (2 equiv), silylating reagent ( 2 equiv), and DBU (4 equiv) in THF $(0.5 \mathrm{~mL}$ ) was stirred at room temperature (rt) for $30 \mathrm{~min}$ (solution A). A boron source (B: $20 \mathrm{~mol} \%$ ) and a ligand (20 mol \%) in THF $(0.5 \mathrm{~mL})$ were stirred at rt for $30 \mathrm{~min}$ in another vessel (solution B). Solution B and 3a (1 equiv) were added successively to solution $\mathrm{A}$, and the mixture was stirred at $\mathrm{rt}$ for $12 \mathrm{~h}$. ${ }^{b}$ In toluene. ${ }^{c}$ The silylating reagent was added as the final component. ${ }^{d} \mathrm{DBU}$ (3.5 equiv) and $0.1 \mathrm{M}$. 
Table 2. Substrate Scope ${ }^{a}$

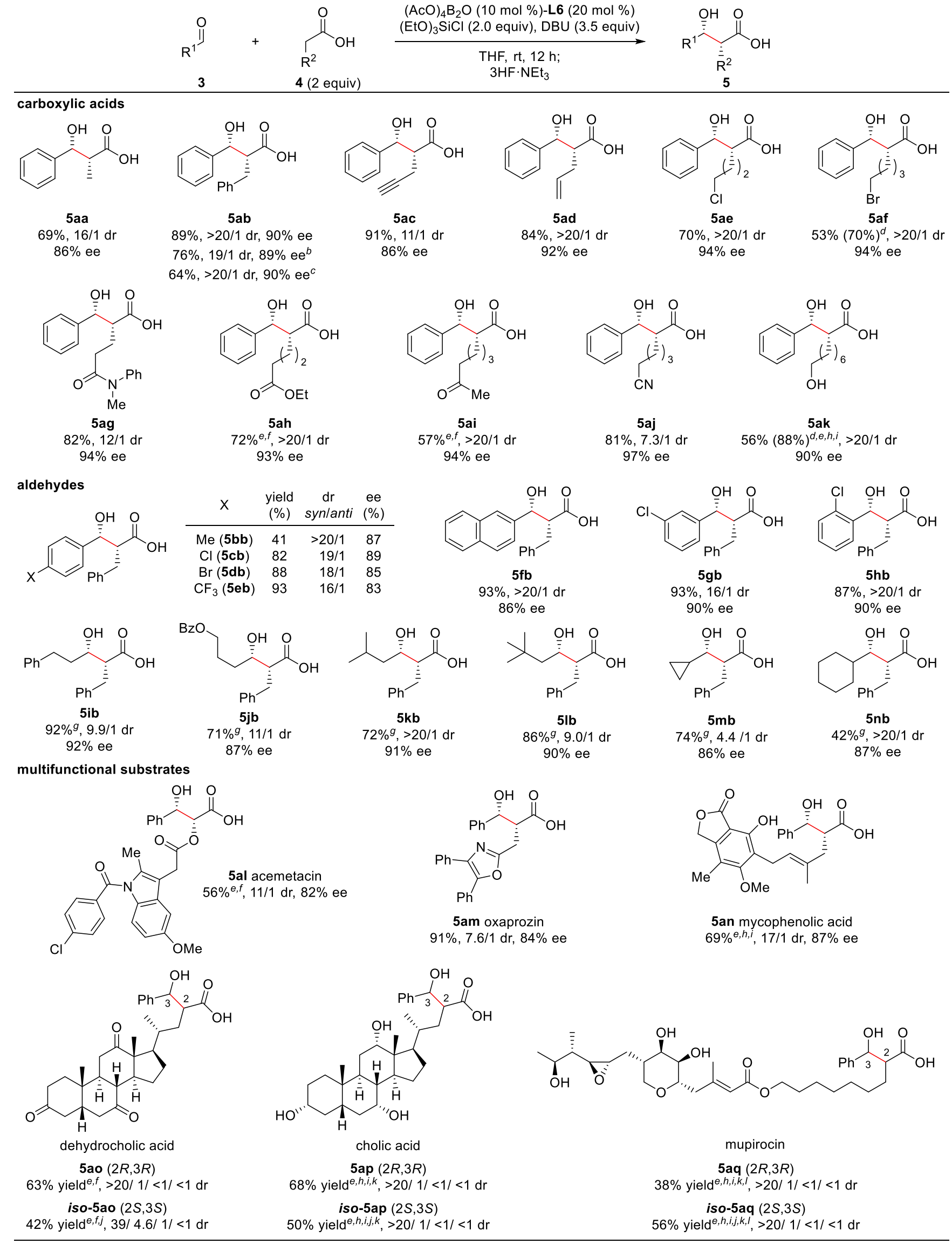


${ }^{a}$ General reaction conditions: $4(0.60 \mathrm{mmol}), 3(0.30 \mathrm{mmol}),(\mathrm{EtO}){ }_{3} \mathrm{SiCl}(0.60 \mathrm{mmol}), \mathrm{DBU}(1.05 \mathrm{mmol}),(\mathrm{AcO}){ }_{4} \mathrm{~B}_{2} \mathrm{O}(0.03 \mathrm{mmol})$, L6 (0.06 mmol), THF (3.0 mL), room temperature, $12 \mathrm{~h}$. Isolated yield, enantiomeric excess (ee), and diastereomeric ratio (dr) shown in the Table were determined after conversion to the corresponding methyl esters, except for 5 ak. ${ }^{16 b} 4 \mathrm{~mol} \%(\mathrm{AcO})_{4} \mathrm{~B}_{2} \mathrm{O}$ and $8 \mathrm{~mol} \%$ L6 were used. ${ }^{c} 6$ mmol scale reaction. ${ }^{d} \mathrm{NMR}$ yield is shown in parentheses. ${ }^{e}$ Concentration was $0.2 \mathrm{M} .{ }^{f} 4$ equiv of DBU was used. ${ }^{g}$ Concentraion was $0.3 \mathrm{M}$, and 5 equiv of DBU was used. ${ }^{h} 4$ equiv of $(\mathrm{EtO})_{3} \mathrm{SiCl}$ was used. ${ }^{i} 6$ equiv of DBU was used. ${ }^{j}$ ent-L6 was used. ${ }^{k} 10$ equiv of aldehyde 3 was used. ${ }^{l} 30$ mol \% $(\mathrm{AcO})_{4} \mathrm{~B}_{2} \mathrm{O}$ and $60 \mathrm{~mol} \%$ L6 were used.

Finally, we applied our method to more complex carboxylic acids containing multiple functional groups. By using commercially available NSAIDs, acemetacin (4l) and oxaprozin (4m), the corresponding aldol products 5al and 5am were obtained in high yield and selectivity. An immunosuppessant drug, mycophenolic acid (4n), containing a phenolic hydroxy group afforded 5an in $69 \%$ yield with $17 / 1 \mathrm{dr}$ and $87 \%$ ee. The reaction between 3a with dehydrocholic acid (4o) bearing three keto groups proceeded chemoselectively at the $\alpha$-position of the carboxyl group. The reaction was stereodivergent, producing isomeric products depending on the chirality of the boron catalyst: using ligand L6 or ent-L6, product 5 ao or iso-5ao was obtained in high stereoselectivity, respectively. Cholic acid bearing three hydroxy groups afforded products 5ap and iso-5ap in excellent selectivity, which was again controlled by the catalyst. The stereodivergent reaction also proceeded from mupirocin, an antibiotic drug containing hydroxy, epoxy, $\alpha, \beta$-unsaturated ester, and carboxyl groups, in high chemo- and stereoselectivity (5aq and iso-5aq).

\section{Scheme 2. Comparison between Siloxy Ester and $t$ Bu Es-} ter
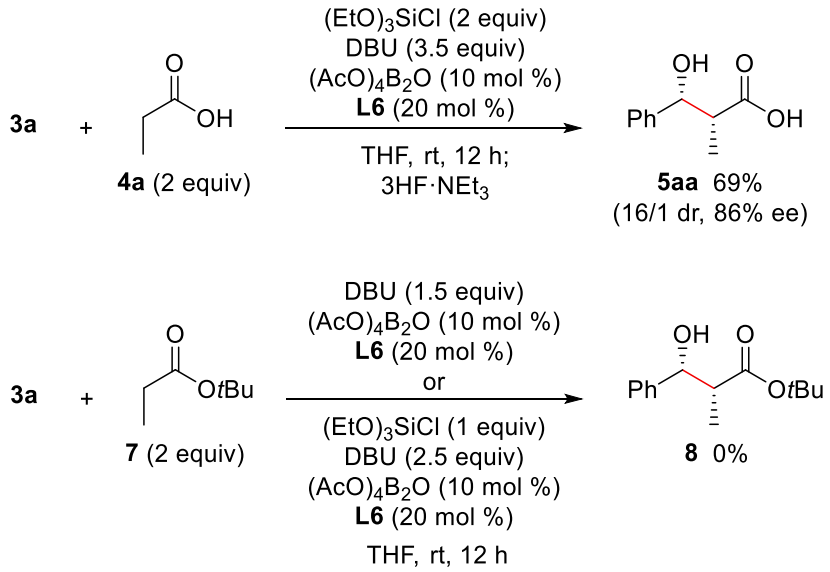

To gain mechanistic insights, we conducted a series of experiments. First, we compared the reactivity between siloxy esters and alkyl esters. Whereas the reaction between aldehyde 3a and carboxylic acid 4a proceeded to afford product 5aa in $69 \%$ yield through the corresponding siloxy ester, the reaction between $\mathbf{3 a}$ and $t \mathrm{Bu}$ ester $\mathbf{7}$ did not proceed at all, irrespective of the presence or absence of $(\mathrm{EtO})_{3} \mathrm{SiCl}$ (Scheme 2). The acidity of carbonyl $\alpha$-proton may dictate the contrasting reactivity: calculated $\mathrm{p} K_{\mathrm{a}}$ values for $\mathrm{CH}_{3} \mathrm{COOSi}(\mathrm{OEt})_{3}$ and $\mathrm{CH}_{3} \mathrm{COO} t \mathrm{Bu}$ were 20 and 26, respectively. ${ }^{16,18}$ The significantly higher acidity of siloxy esters compared to alkyl esters might be partly due to divalent coordination of carboxylate to a hypervalent silicone atom, which was previously proposed by Yamamoto and colleagues on the basis of ${ }^{29} \mathrm{Si} \mathrm{NMR}$ in mechanistic studies of the silyl ester-mediated peptide coupling reaction. ${ }^{19}$

\section{Scheme 3. Inhibitory Effects of Carboxylate}

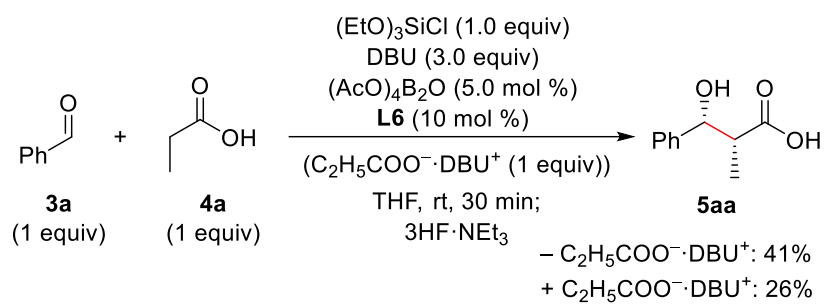

\section{Scheme 4. Acceleration of Mannich and Allylation Reac- tions by Siloxy Ester Formation}
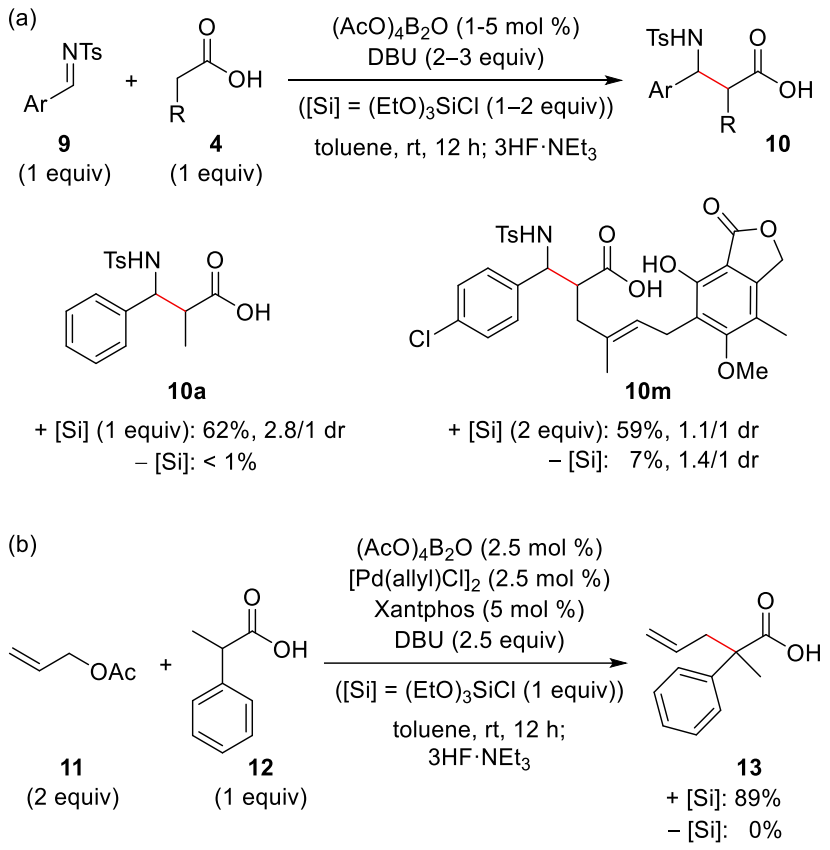

Acidification of the $\alpha$-proton of carboxylic acids may not be the sole cause for rate acceleration by the silylating reagent, however. During the initial optimization, we noticed that increasing the amount of carboxylate decreased the reactivity. Inhibitory effects of an excess carboxylate were likely due to coordination to the boron catalyst, which attenuated its Lewis acidity by forming a borate. The following experiments support our hypothesis (Scheme 3); whereas 5aa was obtained in $41 \%$ yield for 30 min under the standard conditions, yield decreased to $26 \%$ in the presence of 1 equiv propionate. Therefore, silyl ester formation would decrease the detrimental coordination of free carboxylate to the boron catalyst.

If the acceleration effects of silylating reagents are caused by acidification of the $\alpha$-proton and/or attenuation of the carboxylate coordination to the boron catalyst through silyl ester formation, the effects would be general for other boron-catalyzed $\alpha$-functionalizations of carboxylic acids. Therefore, we applied 
the present conditions to previously developed reactions, ${ }^{7}$ and found that this is indeed the case (Scheme 4). Mannich reaction $^{7 \mathrm{a}}$ between 9 and $\mathbf{4 a}$ or $\mathbf{4 m}$ proceeded in the presence of 2 mol \% boron catalyst and $(\mathrm{EtO})_{3} \mathrm{SiCl}$, producing $10 \mathrm{a}$ or $10 \mathrm{~m}$ in $62 \%$ or $59 \%$ yield, respectively (Scheme $4 \mathrm{a}$ ). Allylation reaction $^{7 \mathrm{~b}}$ between $\mathbf{1 1}$ and $\mathbf{1 2}$ afforded $\mathbf{1 3}$ in $89 \%$ yield using 5 mol \% boron catalyst and $5 \mathrm{~mol} \%$ palladium catalyst in the presence of $(\mathrm{EtO})_{3} \mathrm{SiCl}$ (Scheme $4 \mathrm{~b}$ ). The products were obtained in up to only $7 \%$ yield under the previous conditions without the silylating reagent.

\section{Scheme 5. Effects of (EtO) ${ }_{3} \mathrm{SiCl}$ on Relationships be- tween Enantiomeric Excesses of Catalyst and Products in Mannich Reaction}

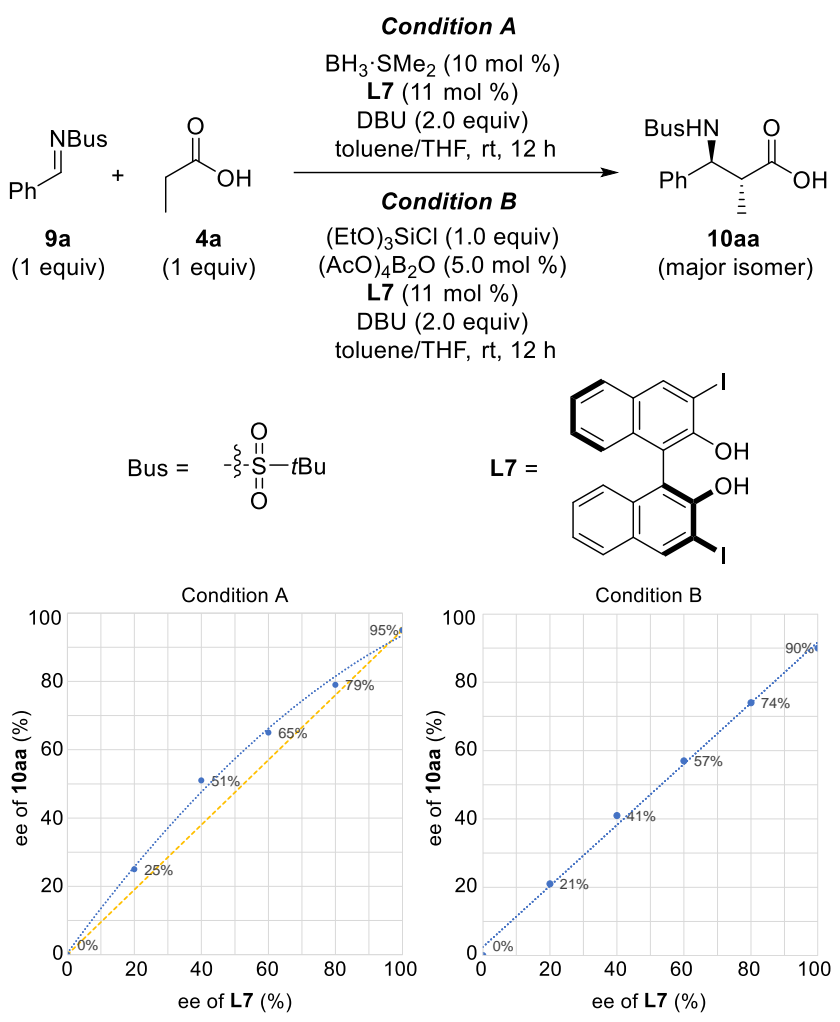

We propose the active nucleophile for this catalytic asymmetric aldol reaction to be chiral $\mathrm{Si} / \mathrm{B}$ enediolate 2 based on the following non-linear effects experiments. ${ }^{20} \mathrm{We}$ first observed a linear relationship between enantiomeric excesses of the catalyst $(20,40,60,80$, and $>99 \%$ ee) and product $\mathbf{5 a b}(19,36,54$, 71 , and $90 \%$ ee, respectively) for the aldol reaction between $3 \mathbf{a}$ and $\mathbf{4 b}$ in the presence of $(\mathrm{EtO})_{3} \mathrm{SiCl}{ }^{16}$ Because the catalytic aldol reaction did not proceed in the absence of $(\mathrm{EtO})_{3} \mathrm{SiCl}(\mathrm{Ta}-$ ble 1 , entry 2), however, it was not possible to compare this result to control conditions in the absence of $(\mathrm{EtO})_{3} \mathrm{SiCl}$. Therefore, we investigated boron-catalyzed asymmetric Mannich reaction using BINOL-derived ligand L7, ${ }^{7 \mathrm{a}}$ an optimized chiral ligand for the Mannich reaction, which proceeded either in the absence or the presence of $(\mathrm{EtO})_{3} \mathrm{SiCl}$ (Scheme 5). Positive non-linear effects were observed in the absence of $(\mathrm{EtO})_{3} \mathrm{SiCl}$ (Condition A), supporting our idea that the reaction proceeds through diboron enediolate 1 . In the presence of $(\mathrm{EtO})_{3} \mathrm{SiCl}$ (Condition B), however, the relationship was linear. Thus, the reaction may not involve intermediates or active species containing more than one boron atom. The most probable active species is $\mathrm{Si} / \mathrm{B}$ enediolate 2 . The fact that enantio- and diastereoselectivity depended on the silyl group (Table 1, entries 5 and 6 ) is also consistent with the hypothesis that the silyl group is involved in the stereo-determining step.

We then performed density functional theory (DFT) calculations to rationalize the overall reaction pathway. ${ }^{16}$ Computed free energy profile is shown in Figure 1. First, we searched possible intermediates for deprotonation of triethoxysilyl ester derived from 4a (Figure S1). ${ }^{16}$ Among them, deprotonation of $\mathbf{I}_{\mathbf{1}}$, where the siloxy ester coordinated to the Lewis acidic chiral boron catalyst, showed the lowest free energy barrier ( $\mathbf{T S}_{\mathbf{1}}, 4.1$ $\mathrm{kcal} / \mathrm{mol}$, Figure 2A). Other intermediates furnished relatively large free energy barriers. Therefore, we chose $\mathbf{I}_{1}$ as the starting point of the reaction pathway. After deprotonation, intermediate $\mathbf{I}_{2}$, which was $8.2 \mathrm{kcal} / \mathrm{mol}$ more stable than $\mathbf{I}_{1}$, was formed. Then, reconstitution of $\mathbf{I}_{2}$ generated $\mathrm{Si} / \mathrm{B}$ hetero enediolate intermediate $\mathbf{I}_{\mathbf{3}}$ or $\mathbf{I}_{\mathbf{4}}$ with only 3.3 or $5.9 \mathrm{kcal} / \mathrm{mol}$ higher energy than $\mathbf{I}_{2}$, respectively. Because the energy difference between $\mathbf{I}_{3}$ and $\mathbf{I}_{\mathbf{4}}$ was only $2.6 \mathrm{kcal} / \mathrm{mol}$, we searched transition states for the asymmetric aldol reaction starting from $\mathbf{I}_{\mathbf{3}}$ or $\mathbf{I}_{\mathbf{4}}$.

The asymmetric aldol reaction from $\mathbf{I}_{3}$ proceeded in an innersphere fashion through a six-membered chair transition state $\mathbf{T S}_{2}$, which was only $4.4 \mathrm{kcal} / \mathrm{mol}$ higher energy than $\mathbf{I}_{\mathbf{3}}$ (Figure 2B). We also calculated an outer-sphere transition state from $\mathbf{I}_{4}$ and aldehyde $\mathbf{3 a}$ coordinating to another chiral boron complex. The transition state was, however, $11.7 \mathrm{kcal} / \mathrm{mol}$ higher than $\mathbf{T S}_{2}$, indicating that the outer-sphere mechanism did not contribute to the reaction. Thus, we concluded that the asymmetric aldol reaction proceeded through $\mathbf{I}_{3}$ and $\mathbf{T S}_{2}$, leading to the $(2 R, 3 R)$-product. Among calculated transition states, $\mathbf{T S}_{\mathbf{2}}$ existed in $80 \%$ probability. ${ }^{16}$ Other transition states affording $(2 S, 3 S)-,(2 R, 3 S)$-, and $(2 S, 3 R)$-products existed in $12.5 \%, 7.5 \%$, and $0 \%$ probabilities, respectively. Thus, the calculated syn/anti ratio was 93/7. This value is consistent with the experimental result of 16/1 dr for 5aa (Table 2). Furthermore, the computed ee value was $73 \%$, which is qualitatively in good agreement with the experimental data (86\% ee).

After asymmetric aldol reaction, boron aldolate $\mathbf{I}_{5}$ with 29.1 $\mathrm{kcal} / \mathrm{mol}$ below the entry point (I $\left.\mathbf{I}_{1}\right)$ was generated. Due to the existence of an oxophilic silyl group in the molecule, ligand exchange proceeded between boron and silicon atoms in $\mathbf{I}_{5}$ to generate a catalytically active boron carboxylate $\mathbf{I}_{7}$, which was only $1.7 \mathrm{kcal} / \mathrm{mol}$ higher energy than $\mathbf{I}$. 


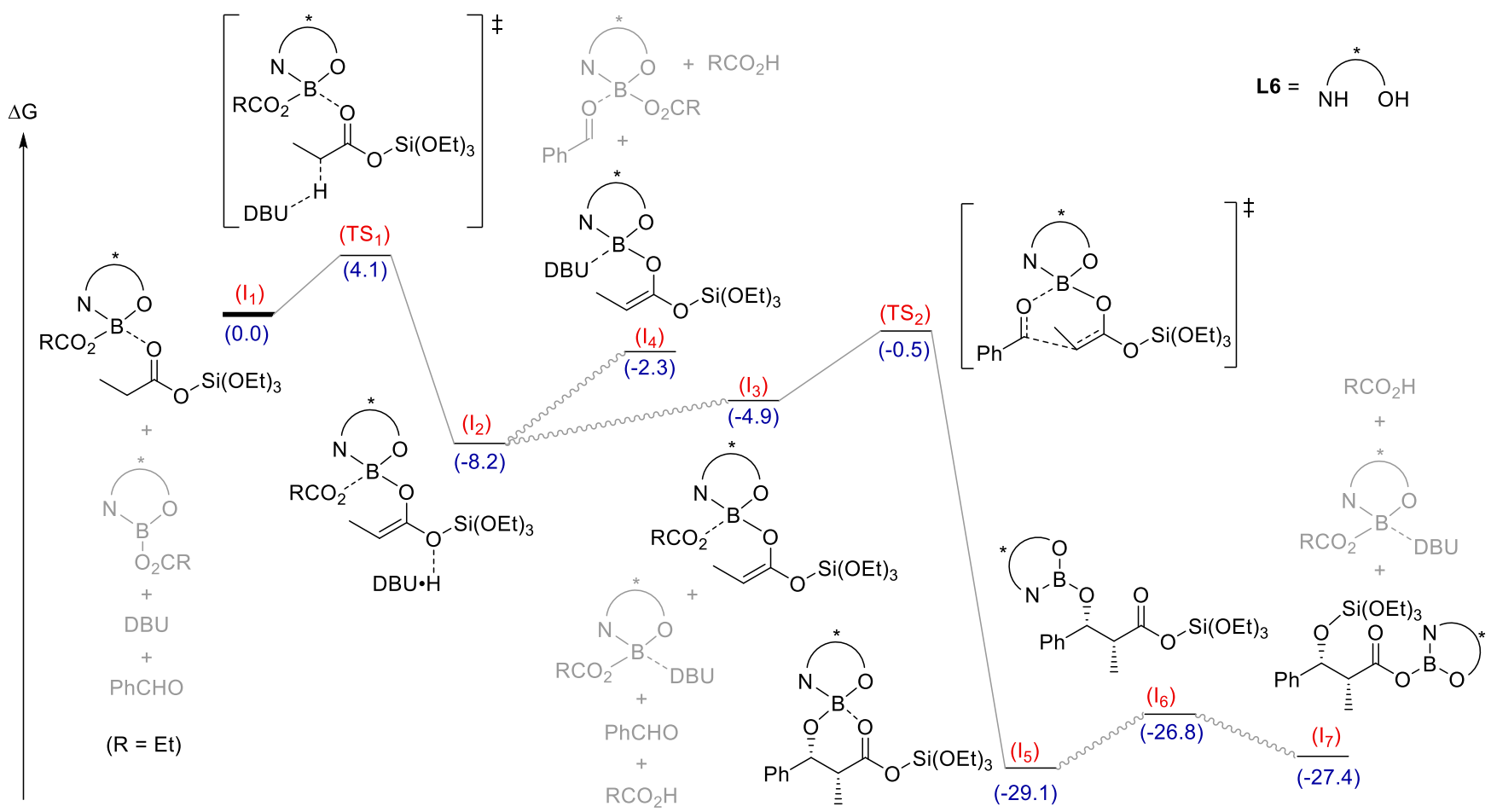

Figure 1. Computed free energy profile for the boron-catalyzed asymmetric aldol reaction. Relative free energies are in kcal/mol.

A
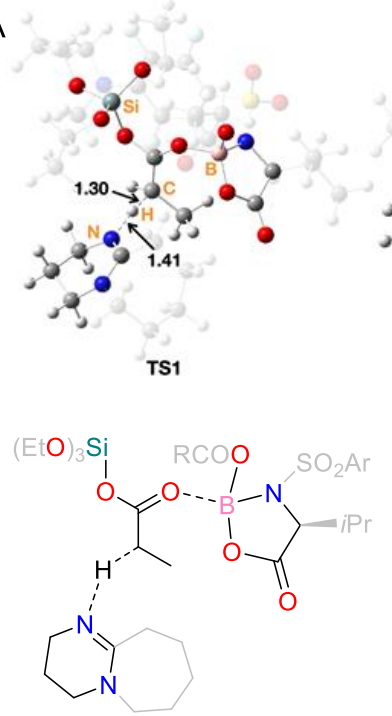

Figure 2. Transition state structures for deprotonation (A: $\mathbf{T S}_{1}$ ) and asymmetric aldol reaction (B: $\mathbf{T S}_{2}$ ) steps.

\section{Conclusions}

We developed a chiral boron-catalyzed, carboxylic acid-selective, and asymmetric aldol reaction, which was for the first time applicable to multifunctional substrates at late stages. The reaction proceeded chemoselectively at the $\alpha$-position of a carboxyl group, even when substrates contained functional groups of intrinsically more acidic protons, such as ketones, esters, nitriles, and amides. Catalyst-controlled stereodivergent reactions were also possible. The transformation of carboxylic acids to siloxy esters in the reaction mixture, which can be easily cleaved in the workup operation, was critical for this catalysis.
Mechanistic studies suggested three main roles of the siloxy ester formation: 1) acidification of the $\alpha$-proton for acceleration of the enolization step, 2) attenuation of detrimental coordination of carboxylate to the boron catalyst, and 3) facilitation of the catalyst turnover through silylation of the boron aldolate intermediate. DFT calculations confirmed that deprotonation of the siloxy ester has a low energy barrier, and the subsequent asymmetric aldol reaction between the $\mathrm{Si} / \mathrm{B}$ hetero enediolate intermediate and aldehydes proceeded in an inner sphere fashion. The computed reaction selectivity was consistent with the experimental results. We are currently applying this method to late-stage diversification of complex natural products to identify new compounds with better pharmaceutical properties.

\section{ASSOCIATED CONTENT}

\section{Supporting Information}

The Supporting Information is available free of charge at https://pubs.acs.org/doi/10.1021/

All data including experimental procedures and compound characterization, NMR, and HPLC are available (PDF).

\section{AUTHOR INFORMATION}

\section{Corresponding Authors}

Harunobu Mitsunuma - Graduate School of Pharmaceutical Sciences, The University of Tokyo, Tokyo 113-0033, Japan; orcid.org/0000-0001-7609-905X; Email: hmitsunuma@g.ecc.u-tokyo.ac.jp

Motomu Kanai - Graduate School of Pharmaceutical Sciences, The University of Tokyo, Tokyo 113-0033, Japan; 
orcid.org/0000-0003-1977-7648; Email: kanai@mol.f.u-tokyo.ac.jp

\section{Authors}

Taiki Fujita - Graduate School of Pharmaceutical Sciences, The University of Tokyo, Tokyo 113-0033, Japan.

Mina Yamane - Graduate School of Pharmaceutical Sciences, The University of Tokyo, Tokyo 113-0033, Japan.

W. M. C. Sameera - Institute of Low Temperature, The Hokkaido University, Sapporo 060-0819, Japan.

\section{Notes}

The authors declare no competing financial interest.

\section{ACKNOWLEDGMENT}

We acknowledge Yuya Morita, Hideoki Nagai and Yohei Shimizu in The University of Tokyo for studying non-linear effects of Mannich reaction (Scheme 3b). This work was supported by JSPS KAKENHI Grant Numbers JP17H06441 and JP17H06442 (Hybrid Catalysis) (M.K.), JP20H05843 (Dynamic Exciton) and JP21K15220 (H.M.), and 19J22372 (JSPS fellowships), The ANRI fellowship, and Sato Scholarship (T.F.). The computation was performed at the Research Center for Computational Science, Okazaki, Japan. Supercomputing resources at the Research Center for Computational Science at Okazaki (Japan) and the Academic Center for Computing at Media Studies at Kyoto University (Japan) are acknowledged.

\section{REFERENCES}

(1) (a) Lamberth, C.; Dinges, J. Bioactive Carboxylic Compound Classes: Pharmaceuticals and Agrochemicals; Lamberth, C.; Dinges, J., Eds.; Wiley-VCH: Weinheim, 2016; pp 1-11. (b) Rao, P. P. N.; Kabir, S. N.; Mohamed, T. Nonsteroidal Anti-Inflammatory Drugs (NSAIDs): Progress in Small Molecule Drug Development. Pharmaceuticals, 2010, 3, 1530-1549.

(2) Walsh, C.; Wencewicz, T. Antibiotics: Challenges, Mechanisms, Opportunities.; ASM press: Washington, DC, 2016; pp 1-29.

(3) Hong, B.; Luo, T.; Lei, X. Late-Stage Diversification of Natural Products. ACS Cent. Sci. 2020, 6, 622-635.

(4) Ishihara, K.; Ohara, S.; Yamamoto, H. 3,4,5-Trifluorobenzeneboronic Acid as an Extremely Active Amidation Catalyst. J. Org. Chem. 1996, 61, 4196-4197.

(5) For selected examples of organoboron-catalyzed amide condensation, see; (a) Maki, T.; Ishihara, K.; Yamamoto, H. Arylboronic Acid-Catalyzed Direct Condensation of Carboxylic Acids with Ureas Synlett 2004, 2004, 1355-1358. (b) Maki, T.; Ishihara, K.; Yamamoto, H. 4,5,6,7-Tetrachlorobenzo[d][1,3,2]dioxaborol-2-ol as an Effective Catalyst for the Amide Condensation of Sterically Demanding Carboxylic Acids. Org. Lett. 2006, 8, 1431-1434. (c) Arnold, K.; Davies, B.; Giles, R. L.; Grosjean, C.; Smith, G. E.; Whiting, A. To Catalyze or Not to Catalyze? Insight into Direct Amide Bond Formation from Amines and Carboxylic Acids under Thermal and Catalyzed Conditions. Adv. Synth. Catal. 2006, 348, 813-820. (d) Arnold, K.; Davies, B.; Hérault, D.; Whiting, A. Asymmetric Direct Amide Synthesis by Kinetic Amine Resolution: A Chiral Bifunctional Aminoboronic Acid Catalyzed Reaction between a Racemic Amine and an Achiral Carboxylic Acid. Angew. Chem., Int. Ed. 2008, 47, 2673-2676. (e) Al-Zoubi, R. M.; Marion, O.; Hall, D. G. Direct and Waste-Free Amidations and Cycloadditions by Organocatalytic Activation of Carboxylic Acids at Room Temper-ature. Angew. Chem., Int. Ed. 2008, 47, 2876-2879. (f) Gernigon, N.; Al-Zoubi, R. M.; Hall, D. G. Direct Amidation of Carboxylic Acids Catalyzed byortho-Iodo Arylboronic Acids: Catalyst Optimization, Scope, and Preliminary Mechanist Study Supporting a Peculiar Halogen Acceleration Effect. J. Org. Chem. 2012, 77, 8386-8400. (g) Yamashita, R.; Sakakura, A.; Ishihara, K. Primary Alkylboronic Acids as Highly Active Catalysts for the Dehydrative Amide Condensation of $\alpha$-Hydroxycarboxylic Acids. Org. Lett. 2013, 15, 3654-3657. (h) Tam, E. K. W.; Rita; Liu, L. Y.; Chen, A. 2-Furanylboronic Acid as an Effective Catalyst for the Direct Amidation of Carboxylic Acids at Room Temperature. Eur. J. Org. Chem. 2015, 2015, 1100-1107. (i) Mohy El Dine, T.; Erb, W.; Berhault, Y.; Rouden, J.; Blanchet, J. Catalytic Chemical Amide Synthesis at Room Temperature: One More Step Toward Peptide Synthesis. J. Org.Chem. 2015, 80, 4532-4544. (j) Ishihara, K.; Lu, Y. Boronic Acid-DMAPO Cooperative Catalysis for Dehydrative Condensation between Carboxylic Acid and Amines. Chem. Sci. 2016, 7, 1276-1280. (k) Noda, H.; Furutachi, M.; Asada, Y.; Shibasaki, M.; Kumagai,N. Unique Physicochemical and Catalytic Properties Dictated by the $\mathrm{B}_{3} \mathrm{NO}_{2}$ Ring System. Nat. Chem. 2017, 9, 571-577. (l) Wang, K.; Lu,Y.; Ishihara, K. Theortho-Substituent on 2,4-Bis(trifluoromethyl)-phenylboronic Acid Catalyzed Dehydrative Condensation between Carboxylic Acids and Amines. Chem. Commun. 2018, 54, 5410-5413. (m) Sawant, D. N.; Bagal, D. B.; Ogawa, S.; Selvam, K.; Saito, S. Diboron-Catalyzed Dehydrative Amidation of Aromatic Carboxylic Acids with Amines. Org. Lett. 2018, 20, 43974400. (n) Opie, C. R.; Noda, H.; Shibasaki, M.; Kumagai, N. All NonCarbon $\mathrm{B}_{3} \mathrm{NO}_{2}$ Exotic Heterocycles: Synthesis, Dynamics, and Catalysis. Chem. - Eur. J. 2019, 25, 4648-4653. (o) Shimada, N.; Hirata, M.; Koshizuka, M.; Ohse, N.; Kaito, R.; Makino, K. Diboronic Acid Anhydrides as Effective Catalysts for the Hydroxy-Directed Dehydrative Amidation of Carboxylic Acids. Org. Lett. 2019, 21, 4303-4308. (p) Michigami, K.; Sakaguchi, T.; Takemoto, Y. Catalytic Dehydrative Peptide Synthesis with gem-Diboronic Acids. ACS Catal. 2020 10, 683-688.

(6) (a) Wang, D.-H.; Yu, J.-Q. Highly Convergent Total Synthesis of (+)-Lithospermic Acid via a Late-Stage Intermolecular C-H Olefination. J. Am. Chem. Soc. 2011, 133, 5767-5769. (b) Rosen, B. R.; Simke, L. R.; Thuy-Boun, P. S.; Dixon, D. D.; Yu, J.-Q.; Baran, P. S. CH Functionalization Logic Enables Synthesis of $(+)$-Hongoquercin A and Related Compounds. Angew. Chem., Int. Ed. 2013, 52, 73177320. (c) Meng, G.; Lam, N. Y. S. Lucas, E. L. Saint-Denis, T. G.; Verma, P.; Chekshin, N.; Yu, J.-Q. Achieving Site-Selectivity for C-H Activation Processes Based on Distance and Geometry: A Carpenter's Approach. J. Am. Chem. Soc. 2020, 142, 10571-10591.

(7) (a) Morita, Y.; Yamamoto, T.; Nagai, H.; Shimizu, Y.; Kanai, M. Chemoselective Boron-Catalyzed Nucleophilic Activation of Carboxylic Acids for Mannich-Type Reactions. J. Am. Chem. Soc. 2015, 137, 7075-7078. (b) Fujita, T.; Yamamoto, T.; Morita, Y.; Chen, H.; Shimizu, Y.; Kanai, M. Chemo- and Enantioselective Pd/B Hybrid Catalysis for the Construction of Acyclic Quaternary Carbons: Migratory Allylation of $O$-Allyl Esters to $\alpha$-C-Allyl Carboxylic Acids. J. Am. Chem. Soc. 2018, 140, 5899-5903.

(8) For iron/alkali metal-catalyzed enolization and $\alpha$-oxidation of carboxylic acids, see; Tanaka, T.; Yazaki, R.; Oshima, T. Chemoselective Catalytic $\alpha$-Oxidation of Carboxylic Acids: Iron/Alkali Metal Cooperative Redox Active Catalysis. J. Am. Chem. Soc. 2020, 142, 4517-4524.

(9) (a) Evans, D. A.; Nelson, J. V.; Vogel, E.; Taber, T. R. Stereoselective Aldol Condensations via Boron Enolates. J. Am. Chem. Soc. 1981, 103, 3099-3111. (b) Brown, H. C.; Dhar, R. K.; Ganesan, K.; Singaram, B. Enolboration. 1. Dicyclohexylchloroborane/Triethylamine as a Convenient Reagent for Enolboration of Ketones and Other Carbonyl Derivatives. J. Org. Chem. 1992, 57, 499-504. (c) Ramachandran, P. V.; Chanda, P. M.; Otoo, B. Irreversible aldolization of ketones with bisdicyclohexylboron enediolates. Tetrahedron Lett. 2019, 60, 151102.

(10) (a) Nagai, H.; Morita, Y.; Shimizu, Y.; Kanai, M. Ligand-Promoted, Boron-Mediated Chemoselective Carboxylic Acid Aldol Reaction. Org. Lett. 2016, 18, 2276-2279. (b) Ishizawa, K.; Nagai, H.; Shimizu, Y.; Kanai, M. Boron-Catalyzed Carboxylic Acid-Selective Aldol Reaction with Trifluoromethyl Ketone. Chem. Pharm. Bull. 2018, 66, 231-234.

(11) Kotani, S.; Yoshiwara, Y.; Ogasawara, M.; Sugiura, M.; Nakajima, M. Catalytic Enantioselective Aldol Reactions of Unprotected Carboxylic Acids under Phosphine Oxide Catalysis. Angew. Chem., Int 
Ed. 2018, 57, 15877-15881.

(12) For asymmetric aldol reaction of carboxylic acid using a stoichiometric chiral lithium amide base, see: Yu, K.; Lu, P.; Jackson, J. J.; Nguyen, T. A. D.; Alvarado, J.; Stivala, C. E.; Ma, Y.; Mack, K. A.; Hayton, T. W.; Collum, D. B.; Zakarian, A. Lithium Enolates in the Enantioselective Construction of Tetrasubstituted Carbon Centers with Chiral Lithium Amides as Noncovalent Stereodirecting Auxiliaries. J. Am. Chem. Soc. 2017, 139, 527-533.

(13) For selected examples of direct catalytic asymmetric aldol reactions of carboxylic acid derivatives without electron-withdrawing $\alpha$-substituents under proton-transfer conditions, see: (a) Evans, D. A.; Downey, C. W.; Hubbs, J. L. Ni (II) Bis(oxazoline)-Catalyzed Enantioselective Syn Aldol Reactions of $N$-Propionylthiazolidinethiones in the Presence of Silyl Triflates. J. Am. Chem. Soc. 2003 125, 8706-8707. (b) Suto, Y.; Tsuji, R.; Kanai, M.; Shibasaki, M. $\mathrm{Cu}(\mathrm{I})$-Catalyzed Direct Enantioselective Cross Aldol-Type Reaction of Acetonitrile. Org. Lett. 2005, 7, 3757-3760. (c) Saito, S.; Kobayashi, S. Highly anti-Selective Catalytic Aldol Reactions of Amides with Aldehydes. J. Am. Chem. Soc. 2006, 128. 8704-8705. (d) Iwata, M.; Yazaki, R.; Suzuki, Y.; Kumagai, N.; Shibasaki, M. Direct Catalytic Asymmetric Aldol Reaction of Thioamides: Toward a Stereocontrolled Synthesis of 1,3-Polyols. J. Am. Chem. Soc. 2009, 131.1824418245. (e) Saito, A.; Adachi, S; Kumagai, N.; Shibasaki, M. Direct Catalytic Asymmetric Addition of Alkylnitriles to Aldehydes with Designed Nickel-Carbene Complexes. Angew. Chem. Int. Ed. 2021, 60 8739-8743. (f) Kennington, S. C. D.; Teloxa, S. F.; Mellado-Hidalgo, M.; Galeote, O.; Puddu, S.; Bellido, M.; Romea, P.; Urpí, F.; Aullón, G.; Font-Bardia, M. Direct and Enantioselective Aldol Reactions Catalyzed by Chiral Nickel(II) Complexes. Angew. Chem. Int. Ed. 2021, 10.1002/anie.202104352

(14) For reviews on catalytic asymmetric aldol reactions, see: (a) Carreira, E. M.; Fettes, A.; Marti, C. Catalytic Enantioselective Aldol Addition Reactions. Organic Reactions, John Wiley \& Sons, Inc., 2004. (b) Geary, L. M.; Hultin, P. G. The state of the art in asymmetric induction: the aldol reaction as a case study. Tetrahedron: Asymmetry 2009, 20, 131. (c) Trost, B. M.; Brindle, C. S. The direct catalytic asymmetric aldol reaction. Chem. Soc. Rev. 2010, 39, 16001632. (d) Yamashita, Y.; Yasukawa, T.; Yoo, W.-J.; Kitanosono, T.;
Kobayashi, S. Catalytic enantioselective aldol reactions. Chem. Soc. Rev. 2018, 47, 4388-4480.

(15) For catalytic asymmetric decarboxylative aldol reaction applicable to multifunctional aldehydes, see: Magdziak, D.; Lalic, G.; Lee, H. M.; Fortner, K. C.; Aloise, A. D. Shair, M. D. Catalytic Enantioselective Thioester Aldol Reactions That Are Compatible with Protic Functional Groups. J. Am. Chem. Soc. 2005, 127, 7284-7285. The nucleophile was, however, limited to simple methyl malonic acid half thioester.

(16) See Supporting Information for details.

(17) For selected examples of the combined use of amino acid derived ligands and boron reagent, see; (a) Corey, E. J.; Bakshi, R. K.; Shibata, S. Highly enantioselective borane reduction of ketones catalyzed by chiral oxazaborolidines. Mechanism and synthetic implications. J. Am. Chem. Soc. 1987, 109. 5551-5553. (b) Corey, E. J. Loh, T. P. First application of attractive intramolecular interactions to the design of chiral catalysts for highly enantioselective Diels-Alder reactions. J. Am. Chem. Soc. 1991, 113. 8966-8967. (c) Kiyooka, S.; Kaneko, Y.; Komura, M.; Matsuo, H.; Nakano, M. Enantioselective chiral borane-mediated aldol reactions of silyl ketene acetals with aldehydes. The novel effect of the trialkysilyl group of the silyl ketene acetal on the reaction course. J. Org. Chem. 1991, 56, 22762278. (d) Yeung, Y.-Y.; Corey, E. J. A Simple, Efficient, and Enantiocontrolled Synthesis of a Near-Structural Mimic of Platensimycin. Org. Lett. 2008, 10, 3877-3878.

(18) Charif, I. E.; Mekelleche, S. M.; Villemin, D., Mora-Diez, N. Correlation of Aqueous $\mathrm{p} K_{\mathrm{a}}$ Values of Carbon Acids with Theoretical Descriptors: A DFT Study. J. Mol. Struct.: THEOCHEM 2007, 818, 16

(19) Muramatsu, W.; Manthena, C.; Nakashima, E.; Yamamoto, H. Peptide Bond-Forming Reaction via Amino Acid Silyl Esters: New Catalytic Reactivity of an Aminosilane. ACS Catal. 2020, 10, 95949603

(20) Satyanarayana, T.; Abraham, S.; Kagan, H. B. Nonlinear effects in asymmetric catalysis. Angew. Chem. Int. Ed. 2009, 48, 456-494. 


$$
\begin{aligned}
& \text { (cat.) } \\
& \begin{array}{l}
\mathrm{FG}=\text { keto, ester, nitrile } \\
\text { halo, } \mathrm{OH} \text {, epoxy.... }
\end{array}
\end{aligned}
$$

